Revista de la red interuniversitaria de estudios sobre las

literaturas rioplatenses contemporáneas en Francia

15 | 2016

Un año. Literatura argentina 1969

\title{
Traducir, aclimatar, argentinizar: la importación literaria en 1969
}

\section{Alejandrina Falcón}

\section{OpenEdition}

\section{Journals}

Edición electrónica

URL: http://journals.openedition.org/lirico/2947

DOI: $10.4000 /$ lirico.2947

ISSN: 2262-8339

Editor

Réseau interuniversitaire d'étude des littératures contemporaines du Río de la Plata

\section{Referencia electrónica}

Alejandrina Falcón, «Traducir, aclimatar, argentinizar: la importación literaria en 1969 », Cuadernos LIRICO [En línea], 15 | 2016, Puesto en línea el 04 octubre 2016, consultado el 01 mayo 2019. URL : http://journals.openedition.org/lirico/2947; DOI : 10.4000/lirico.2947

Este documento fue generado automáticamente el 1 mayo 2019.

\section{(c) $(1) \ominus$}

Cuadernos LIRICO está distribuido bajo una Licencia Creative Commons Atribución-NoComercialSinDerivar 4.0 Internacional. 


\title{
Traducir, aclimatar, argentinizar: la importación literaria en 1969
}

\author{
Alejandrina Falcón
}

\section{Introducción}

El lugar de la traducción literaria en la década del sesenta no ha sido intensamente explorado aún. Tal vez la historia de las traducciones en el período 1960-1969 quedó opacada por la convicción unánime de que aquellos fueron años gloriosos para el libro escrito en lengua nacional. Ese período, considerado el último favorable para la edición argentina, se habría sostenido en la difusión de la literatura hispanoamericana y habría propiciado la introducción de temáticas nacionales y latinoamericanas en los catálogos de las editoriales argentinas': «En esos días -leemos en La voluntad- se hablaba mucho del boom del libro argentino. En 1967, las editoriales locales habían publicado 3705 títulos -25 millones de ejemplares-, y la proporción de traducciones era menor que nunca» ${ }^{2}$. En 1969 la cifra de títulos publicados es la mayor del período -4554 títulos- con un tiraje promedio de 4979 ejemplares -uno de los más bajos del período- sobre un total de 22.677.915 millones de ejemplares. Pero no existen datos fidedignos sobre la proporción de traducciones publicadas.

Ahora bien, aun cuando durante el «boom del libro argentino» la proporción de traducciones haya sido «menor que nunca», ¿significa esto que la traducción no tuvo un papel activo en la elaboración de repertorios y poéticas locales o en la consolidación y ampliación de un público de lectores? De ningún modo. En enero de 1970, la revista Los Libros publica una encuesta titulada «La literatura en la Argentina». Responden Beatriz Guido, Tomás Eloy Martínez, Eduardo Gudiño Kieffer, Osvaldo Lamborghini, Germán García, entre otros. Interrogado acerca del mejor libro publicado en la Argentina en 1969, Martínez responde: «[E]l reportaje de Masetti sobre Sierra Maestra, el de Rodolfo Walsh sobre el asesinato de Rosendo García, Los poemas de Sidney West de Juan Gelman y algunos uppercuts perfectos de Último Round». Las preferencias del ex jefe de redacción del clausurado semanario Primera Plana incluyen un fenómeno literario que ilustra el modo 
en que se borran en 1969 los límites entre la literatura nativa y la foránea norteamericana a la sazón- o, mejor dicho, el modo en que la escritura directa y la traducción se entrelazan y confunden: Traducciones III Los poemas de Sidney West del poeta, intérprete y traductor Juan Gelman fue publicado por la editorial Galerna en 1969 y reseñado por Juan Sasturain en 1970:

El formal escamoteo de identidad (Gelman se presenta como traductor de otro poeta) encubre, más allá de la pirueta, una voluntad de romper los esquemas, las expectativas, defraudar la previsibilidad y el descanso placentero que produce el reconocimiento de lo consagrado. Además es la afirmación de un credo no patrimonial de la poesía; la denuncia -a lo Borges- de la propiedad privada de la escritura. $^{3}$

En pleno boom de la letra local, un poeta nacional asume la voz de un traductor que vierte a un poeta norteamericano y así se sumerge en una subjetividad representativa «de la poesía rebelde y contestataria norteamericana de la década del sesenta» ${ }^{4}$. El poemario, que es una seudotraducción explícita, constituye algo más que un acontecimiento literario de 1969: viene a señalar la función central de la literatura traducida en la producción de poéticas locales, es decir, la productividad de la traducción en la construcción de una literatura nacional.

Así el año 1969 constituye una plataforma adecuada para observar de qué modo la literatura argentina, como toda literatura periférica, se construye al ritmo de la traducción de otras literaturas y de la importación de modelos de pensamiento como constante estructural ${ }^{5}$. Indagar el papel de la traducción presupone, por tanto, reconocer el carácter intrínsecamente internacional de toda cultura nacional. Y la cultura Argentina en 1969 estaba inmersa en un clima modernizador y contestatario que también recorría el mundo. Estudiar la circulación internacional de las ideas y de la literatura a través del análisis de los libros traducidos permite medir la intensidad del diálogo nacional con la tópica discursiva impuesta por el contexto internacional. Por eso, a la hora de examinar las representaciones de la traducción, la traductografía y los modos de traducir en 1969 debemos tener presente el peso ideológico y el impacto imaginario de la revolución cubana y la muerte del che en Bolivia, la revolución cultural china, la resistencia vietnamita al ejército de los Estados Unidos, las movilizaciones pacifistas norteamericanas, la reivindicación pacifista de los derechos civiles de los negros, encabezados por Martin Luther King, asesinado en abril de 1968; la radicalización de esas luchas encarnadas en Malcom X y los panteras negras, considerados «la mayor amenaza interna para la seguridad del país $»^{6}$, así como las por entonces recientísimas rebeliones de los estudiantes franceses en mayo de 1968. Sin embargo, tras el «shock autoritario» desencadenado por la dictadura de Onganía, un factor interno sobredetermina el peso de «lo político» en la selección de los materiales: la esfera pública constituía un espacio discursivo controlado por la censura organizada desde el aparato del estado. El discurso y la práctica de la censura constituidos entre 1966 y 1973 operaron sobre zonas precisas del sistema cultural: lo moral, lo sexual, la familia, la religión y la seguridad nacional, encarnada en la persecución al ubicuo enemigo marxista ${ }^{7}$.

El propósito general de este ensayo es explorar el lugar de la traducción a finales del llamado «boom editorial de la literatura nacional» centrándonos en el año 1969. El abordaje del objeto «la traducción literaria en 1969» se llevará a cabo desde tres perspectivas: las representaciones del traductor y la traducción -complejas, contradictorias, en tensión con la materialidad de las prácticas-; la traductografía y los criterios de selección -triplemente condicionados, por la política internacional, la 
censura y la escasez de recursos-; y las estrategias traductoras desplegadas en los textos, que indagaremos a través de un estudio de caso.

\section{Representaciones del traductor y de la traducción}

Dos encuentros internacionales permiten situar los extremos del amplio abanico de discursos y creencias sobre la traducción vigentes en la Argentina de 1969: la Semana de la Crítica en Cannes y un encuentro del PEN American Club en Nueva York.

El primer vector de representaciones procede del imaginario de la «autodeterminación» opuesta a la «colonización mental» o dependencia cultural. En 1969 el documental La hora de los hornos de Solanas y Getino es proyectado en la VIII Semana de la Crítica del Festival de Cannes. Prohibido en la Argentina hasta 1973, el film circuló de manera clandestina en el circuito local pero fue abiertamente proyectado, y premiado, en diversos festivales de cine internacionales. Su presentación en la Semana de la Crítica de Cannes tuvo repercusiones en La Nación, La Razón y La prensa con motivo de las protestas oficiales del gobierno de Onganía -consulado argentino mediante- que denunciaban la distorsión de la imagen de la Argentina que el film difundía en el extranjero ${ }^{8}$. Paralelamente, una publicación rosarina ofreció otra visión de la repercusión internacional del film: en junioseptiembre de 1969 El lagrimal trifurca tradujo «L'heure des brasiers: L'épreuve du direct», un artículo de Louis Marcorelles aparecido en Cahiers du Cinéma en marzo de ese año. Se trataba de una extensa crítica apologética que condenaba vivamente la lectura oficial y su consiguiente censura:

O La hora de hornos es una aberración, un delirio de intelectuales latinoamericanos; o es un acto revolucionario querido por los autores. No sé cuál será el resultado en el terreno. En el cine hay revolución. [...] Importa -concluía Marcorelles-, a despecho de censuras seniles, difundir lo más ampliamente posible una obra que nos obliga a redefinir nuestra relación con el cine. ${ }^{9}$

La mediación traductora garante de tal difusión -el presumible subtitulado para su proyección en Cannes; la recepción francesa vertida al castellano por El Lagrimal- ilustra la función democratizante de la traducción en espacios discursivos controlados.

Ahora bien, este benéfico cruce de traducciones en torno a La hora de los hornos contrasta con la representación del traductor y de la traducción que el film pone literalmente en escena. En la sección «Los Modelos» de la primera parte, la cámara nos guía hacia el «Salón Pepsi-Cola» donde visualizamos al escritor Manuel Mujica Láinez en plena firma de ejemplares al tiempo que escuchamos su voz en off: «Yo he hecho traducciones [...]. Pero no se trata de saber inglés. Se trata de tener el sentido isabelino». A lo cual el narrador retruca, a traición: «El pensamiento de Mujica Láinez es también el de una intelectualidad sumisa al poder neocolonial. La intelligentsia del sistema. Una elite que traduce al castellano la ideología de los países opresores. Su cultura de segunda mano tiene como coro griego a las capas medias intelectuales. Una elite híbrida, despersonalizada».

La obra de Solanas y Getino, emblema censurado de una época, cristaliza representaciones de la traducción que abrevan en el imaginario del nacional populismo antiimperialista, opuesto al modernismo cosmopolita ${ }^{10}$. Esta concepción reduce la importación ideológica y literaria a mera "copia» de culturas foráneas, repetición " simiesca» e imposición de tradiciones y valores culturales hegemónicos del imperialismo neocolonial. Los traductores, agentes de la oligarquía y la gran burguesía, no son sino 
ejecutores de la violencia de los centros neocoloniales: «Copista traductor, intérprete, cuando más espectador, el intelectual neocolonizado será siempre empujado a no asumir su posibilidad creadora». Si se recuerda que el lema de La hora... es la sentencia de Franz Fanon «todo espectador es un traidor», llegamos a la formulación dóxica «el traductor es un traidor».

El segundo vector de representaciones en 1969 procede del corazón de los USA. Fue recogido en 1976 por la revista Sur, y ha sido de peso en el proceso de constitución de la identidad social de los traductores argentinos, en pugna por la profesionalización de su práctica. En septiembre de 1969 la Comisión de Traducciones del PEN American Center redacta en Nueva York el Manifiesto sobre la traducción, documento en torno al cual se organizó el debate de la Conferencia sobre Traducción Literaria realizada en esa misma ciudad en la primavera de 1970. En 1976 la revista Sur traduce al castellano el Manifiesto y las actas de la conferencia de Nueva York en el número especial 338-339 titulado Problemas de la Traducción. El Manifiesto sobre la traducción de 1969 cierra ese número de Sur sin duda para que su «llamado a la acción» sea lo último que el lector recuerde. La vigencia de su contenido es pasmosa; el llamado a la acción, contundente: «Los traductores son proletarios de la literatura y nada pueden perder salvo su condición dependiente». De hecho, la conferencia planificada para 1970 tenía por objeto establecer un modelo de contrato y redactar la Carta de Derechos: el cobro de adelantos y beneficios, la mención de su nombre en tapa y en las publicidades del editor, la percepción de una retribución que cubra el costo de las herramientas de trabajo. La propuesta más novedosa del Manifiesto fue la de crear traductorados (para «tener acceso a un estudio profesional constante sobre la teoría y la práctica de la traducción, como ámbito separado de la filología y la lingüística»), programas de becas y premios, así como promover la traducción desde lenguas y literaturas poco difundidas: rusa, china, vietnamita, un reclamo que debe ser leído sobre el trasfondo de la Guerra Fría, de la guerra de Vietnam y la Revolución Cultural china.

En el prólogo al número especial de 1976, Victoria Ocampo advierte que «no nos hubiéramos enterado de estos textos en Sudamérica (salvo unos cuantos especialistas) sin este número de Sur [...]. Sin los traductores muchas cosas del mundo moderno cesarían de funcionar. Tomando como ejemplo una que a todos nos queda a mano: el cine». El círculo de presentaciones e imágenes se cierra, así, con una involuntaria ironía. El ejemplo que ofrece Ocampo parece destinado a visibilizar las contradicciones de la dupla SolanasGetino, y aun llevarlas a su extremo: el documento del PEN Club, que la revista de Victoria Ocampo hizo pasar a la historia nacional, denuncia que el traductor es un «proletario de la literatura», un "peón del juego editorial», un «entenado en la floresta de la literatura».

Los dos vectores de representaciones, divergentes y aun contrapuestos, se proyectan en el tiempo y señalan los extremos que aún hoy tensan el arco de imágenes, mitos y creencias compartidas sobre la función cultural de la traducción y el traductor. Es preciso ahora contrastar estas elaboraciones simbólicas con la realidad, la materialidad, de las prácticas.

\section{Traductografía argentina en 1969}

En el año del Cordobazo se tradujo mucho y de manera significativa. Las traducciones de ciencias sociales, humanidades y literatura fueron numerosísimas. Entre las editoriales que editaron traducciones ese año figuran aquellas nacidas en el período de 1939-1950, como Losada, Sudamericana, Emece, Rueda o Paidós; y otras nuevas, más pequeñas o 
menos visibles, como Rodolfo Alonso Editor, Brújula, Difusión, De La Flor, Siglo XXI, Centro Editor, Ediciones Del Mediodía, Editores Dos, Fabril Editora, Goyanarte, Huemul, Jorge Álvarez, Juárez Editor, Kalendar y Candelabro, La Pléyade, Libera, Merlín, Aires, Nova, Nueva Visión, Paidós, Pasado y Presente, Quetzal, Quintaria, Rueda, Tiempo Contemporáneo, Troquel, entre otras.

Si bien mi análisis se restringirá a la traducción de narrativa y poesía, no quiero dejar de mencionar cuatro tendencias generales de la traductografía en 1969. En primer lugar, el predominio de la importación del estructuralismo, el marxismo y el psicoanálisis en el rubro de las ciencias sociales y humanidades, conforme a la tendencia general del período. En segundo lugar, la producción de traducciones en torno a lo que Horacio Tarcus llamó la «recepción del Mayo francés», que en gran medida fue obra de editoriales independientes ${ }^{11}$. En 1969, este foco de traducciones directamente vinculadas con el contexto internacional se plasmó en el volumen La Imaginación al Poder publicado por el sello Insurrexit de Mario Pellegrini, y Guillermo Shavelzon de Galerna publicó Las luchas estudiantiles en el mundo, en traducción de Noemí Ulla y Margarita Rey. En tercer lugar, el recurso a la traducción de números especiales de revistas extranjeras y su conversión en libro autónomo: Rodolfo Alonso convirtió en libro un número de la revista Arguments y lo tituló La cuestión de los intelectuales; Carlos Pérez publicó Sexualidad y represión, traducción de un número de Partisans, y Paidós editó un número de TelQuel, revista cuya traducción integral publicitó Jorge Álvarez en Los Libros, en julio de 1969, poco antes de que su editorial cerrara y el proyecto abortara ${ }^{12}$.

¿Qué textos literarios fueron traducidos en 1969? ¿De qué lenguas y de qué literaturas proceden las obras incorporadas al circuito de lectura local? ¿Qué géneros predominaron? En principio, se produjeron traducciones de narrativa, ensayo, poesía y teatro de literatura francesa, norteamericana, inglesa, irlandesa, alemana, italiana, griega, finesa, rusa, polaca, checa, china, vietnamita, japonesa, y reediciones de traducciones de literatura brasileña. En cuanto a las lenguas de traducción, predominan las traducciones literarias de lenguas hipercentrales y centrales, como el inglés, el francés ${ }^{13}$ y el alemán ${ }^{14}$. En ínfima pero significativa medida, siguen traducciones de lengua y literatura italiana ${ }^{15}$; rusa $^{16}$, checa ${ }^{17}$, china, japonesa y vietnamita ${ }^{18}$, griega moderna -con una obra de Nikos Kazantzakis- y finesa, con una selección de poetas traducidos por el poeta finés Matti Rossi. Muchas de estas traducciones son indirectas, es decir, fueron hechas a partir de versiones francesas, anglosajonas, alemanas o italianas. También se importaron traducciones hechas en España, factor que multiplica la presencia de traducciones en el mercado. Un fenómeno que debemos señalar pero que no exploraremos aquí fue la reutilización de catálogos de traducciones españolas en el catálogo de editoriales nacionales. Por ejemplo, el Centro Editor de América Latina adquirió el catálogo de traducciones de la española Aguilar. A lo largo de 1969, fueron publicadas en la colección Biblioteca Universal, que acompañaba los fascículos de Capítulo Universal, dirigidos por Luis Gregorich con la asesoría y colaboración de Jaime Rest, Josefina Delgado y Juan Esteban Fasio, traductor de Jarry. Recién en 1970 Capítulo Universal publicaría las traducciones de Horacio, Salustio y Petronio hechas por la profesora de latín y politraductora Ana Goldar, luego exiliada en Barcelona y hoy conocida como Ana Poljak. 


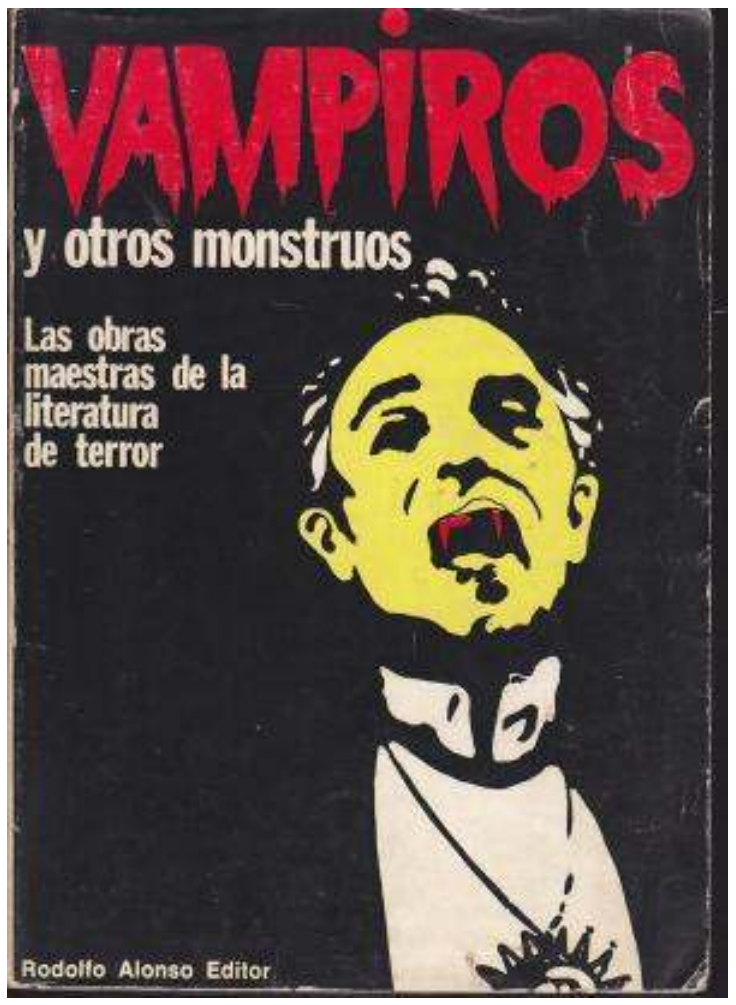

En 1969, predominaron los géneros narrativos pero la poesía tuvo un lugar muy importante en las revistas culturales, como la brevísima El Cielo de César Aira y Arturo Carrera; y en el catálogo de algunas editoriales, como Ediciones del Mediodía y Ediciones Dos. Se observa asimismo traducción de géneros «menores» como el policial clásico y la novela negra ${ }^{19}$, la ciencia-ficción ${ }^{20}$, el terror y la novela gótica -se publicaron dos Frankestein en 1969: uno del profesor cordobés Luis Enrique Revol y el otro de Aníbal Leal${ }^{21}$. Por lo demás, se registra gran interés por la literatura infantil, plasmado en los artículos dedicados al tema en la revista Los Libros -en 1969 se tradujeron dos obras de la Comptesse de Ségur-. También se tradujo literatura erótica, conforme al progresivo interés social por la sexualidad y el erotismo ${ }^{22}$. Tras la publicación de Las lágrimas de Eros de Bataille por Pasado y Presente, el interés en torno al tema quedó plasmado en la colección El Arco de Eros, de la editorial Merlín, que en 1969 editó Física del Amor. Extravagario de la vida sexual de Rémy de Gourmont, Candido o el optimismo de Voltaire y Homosexuario, una antología de textos literarios y ensayísticos sobre homosexualidad masculina y femenina, que mezclaba autores nacionales y extranjeros de todos los tiempos. En este año, la traducción de numerosas obras de y sobre Sade merecería un estudio aparte ${ }^{23}$. 


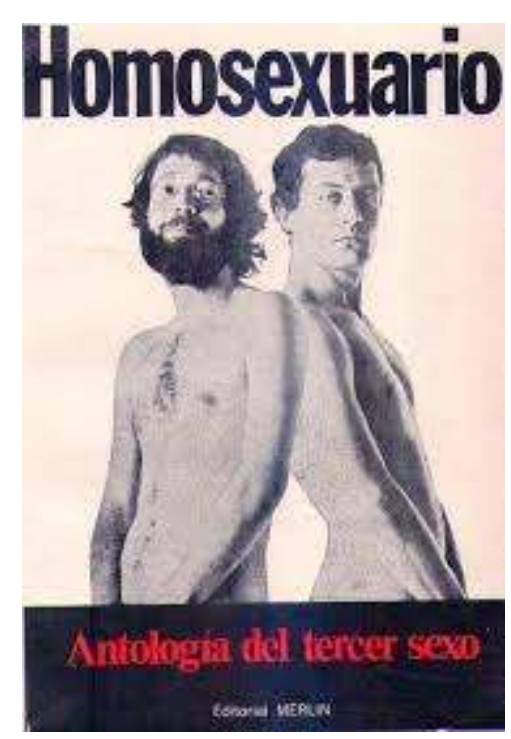

\section{La lengua del imperio: 1969 ¿un año US friendly?}

Daniel Divinsky suele recordar que el exiguo capital inicial con que contaba en 1967 para montar De La Flor tan sólo alcanzaba para contratar los derechos de traducción de tres obras: una de Nizan, una de Brassens y otra cuyos derechos adquirió sin haber siquiera leído el texto original. ¿El motivo? Se trataba de una obra de origen norteamericano. Al parecer, esta decisión obedecía a una hipótesis de Jorge Álvarez:

Si se publicaba -recuerda Divinsky- en los comienzos de la actividad de una editorial un libro de autores de Estados Unidos, se entraba a los ojos del USIS (el Servicio de Informaciones de Estados Unidos con sede por esa época en la Biblioteca Lincoln) en la categoría que se podría haber llamado US friendly y, en consecuencia, el escrutinio del Hermano Grande sobre las ulteriores publicaciones debería ser menos severo. No hay que olvidar que por entonces la Guerra Fría se desarrollaba en escala planetaria y la Argentina del onganiato era un terreno abierto para el campo pro norteamericanos. ${ }^{24}$

Por cierto, este criterio heterónomo de selección sin duda no basta para explicar el lugar de la literatura norteamericana en los catálogos de 1969. Según Alvarado y Rocco Cuzzi, en los sesenta, el anverso complementario de la nacionalización literaria y editorial fue la internacionalización de las lecturas del nuevo público. Este proceso habría producido un «cambio de biblioteca» en virtud del cual fueron privilegiados los escritores norteamericanos ${ }^{25}$. Por cierto, no sólo se tradujeron autores norteamericanos sino también ingleses e irlandeses. 


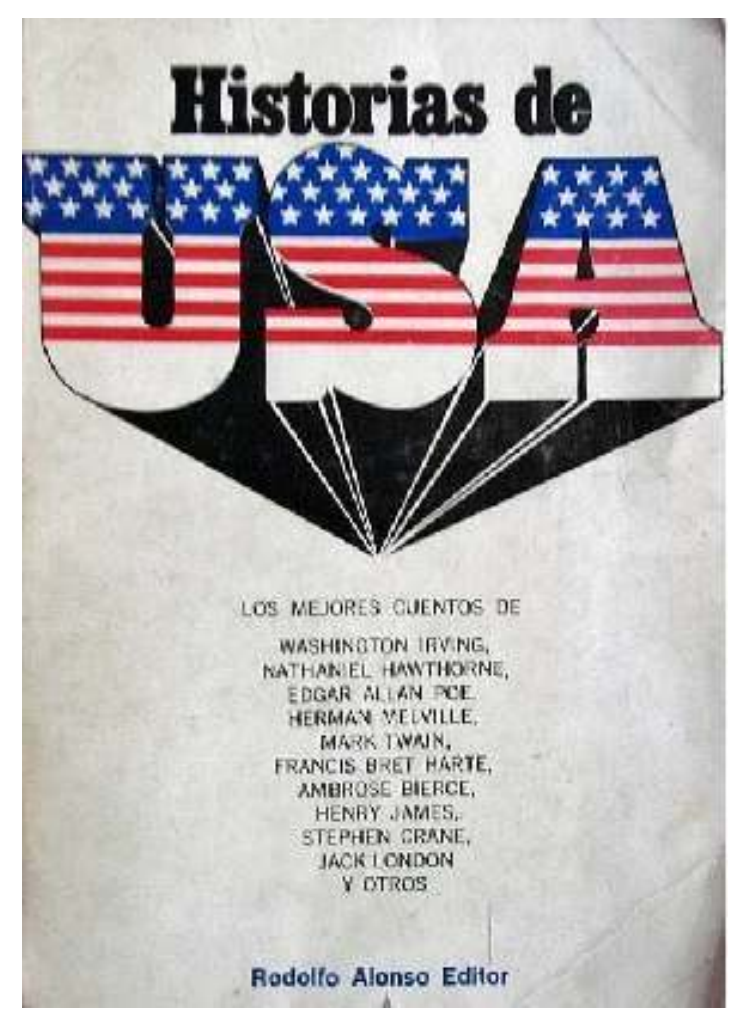

Rodolfo Alonso Editores publicó textos humorísticos de Ambroce Bierce, El llamado de la selva de Jack London en traducción de Hugo A. Brown, revisada por Herman Mario Cueva; El alma del hombre bajo el socialismo de Oscar Wilde, en traducción de Martha de Prengler; de Dylan Thomas, Con distinta piel; de Daniel Dafoe, Diario del año de la peste, reseñado en Los Libros; de Herman Melville, Las encantadas, en traducción de Luis Enrique Revol; Historias de USA es un libro misceláneo -modalidad inaugurada por Jorge Álvarez-. Incluye «fragmentos a manera de prólogo» de Italo Calvino, Elio Vittorini y Cesare Pavese y relatos de Washington Irving, Nathaniel Hawthorne, Edgar Allan Poe, Herman Melville, Fitz James O’Brien, Mark Twain, Francis Bret Harte, Ambrose Bierce, Henry James, Sarah Orne Jewett, O. Henry, Stephen Crane y Jack London, todos ellos en traducción de Hugo. A. Brown. Por su parte, Santiago Rueda publicó Mientras yo agonizo de Faulkner, La vida feliz de F. Macomber Hemingway y Nexus de Henry Miller. Troquel editó una traducción de Robert Frost y Quintaria El escarabajo de oro de Poe. La Editorial Tiempo Contemporáneo editó Antología mínima de Scott Fitzgerald, Cuentos, Porqué estamos en Vietman y Antología mínima de Norman Mailer y dio inicio a la colección Serie Negra con un volumen misceláneo titulado Cuentos policiales de la serie negra. Un conjunto de ensayos introductorios, biográficos o monográficos en traducción vinieron a apuntalar la importación de literatura anglosajona: Nova edita Narrativa actual EEUU de Balakian; Fabril Editora, Jorge Álvarez y Carlos Pérez publican monografías sobre J. D. Salinger, Joyce, Faulkner. Carlos Pérez hace traducir el ensayo de Ian Wats Robinson Crusoe burguesía y novela. 


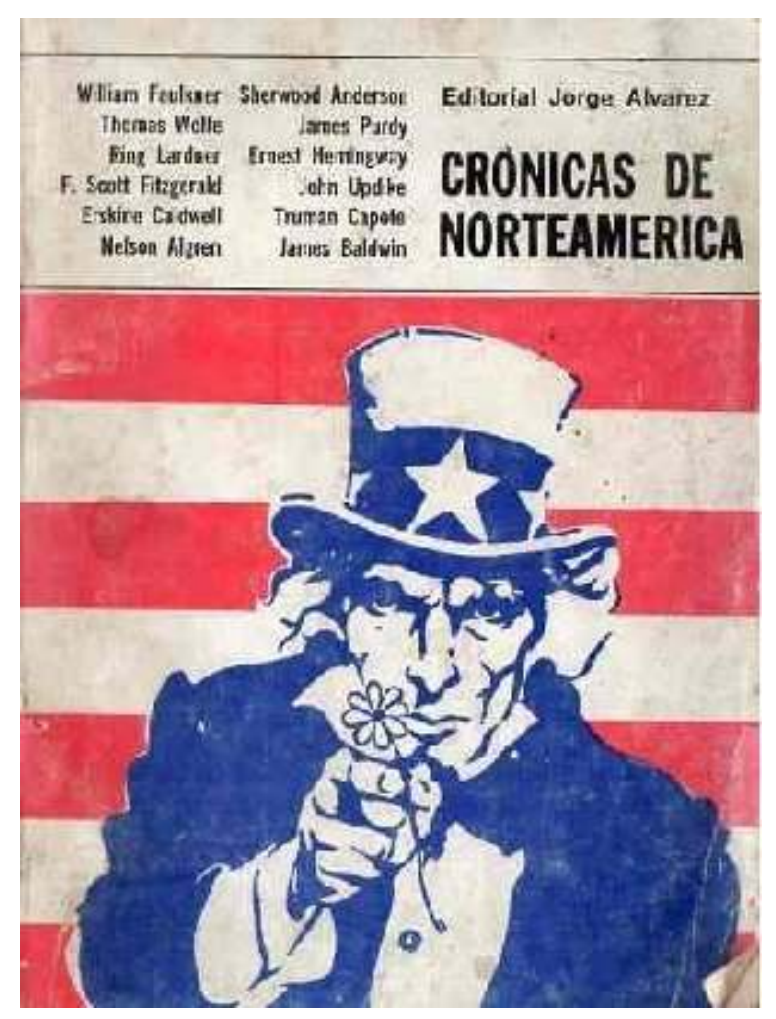

En el ámbito de la traducción de poesía norteamericana, debe destacarse la labor de Marcelo Covián, poeta traductor tenaz, que en los setenta emigró a Barcelona y fue editor de Ariel. En 1969, mientras Covián probablemente trabajaba en la traducción e introducción de la antología Nueva poesía de USA. De Ezra Pound a Bob Dylan, que editó De La Flor en 1970, Ediciones Del Mediodía publicó otras tres antologías con traducciones de su autoría: Allen Ginsberg, Gregory Corso, Lawrence Ferlinghetti, la tríada beat en el año de la muerte de Kerouac. Se trató de un verdadero acontecimiento, tal como recuerda Miguel Grinberg:

[En 1969] apareció una antología de la poesía de Ginsberg que incluía «Kaddish», «Aullido» y otros poemas. Hasta los que más objetaron la dispar traducción de Marcelo Covián se paseaban por la Galería del Este con un ejemplar bajo el brazo. [... ] ¿Por qué tanta trascendencia? Pues porque «Aullido» se refería a una tribu predominantemente norteamericana, pero con equivalencia en todas las latitudes: los jóvenes sofocados por el militarismo y las dictaduras, los artistas incomprendidos, los místicos, los locos, los gays, los amigos reventados, los perdidos en epopeyas alucinógenas, los inmolados en guerras imperiales, los maniáticos sexuales, los anarquistas, los pacifistas, los santos y otros sobrevivientes de lo que el maestro Henry Miller denominó «la pesadilla con aire acondicionado». ${ }^{26}$

Las razones esgrimidas por Grinberg permiten vislumbrar qué motivaba a los editores del sesenta a publicar traducciones de literatura estadounidense, más allá de criterios estéticos y del ardid contra la vigilancia del USIS. Para explicar mejor este criterio de selección quizá debamos retrotraernos a 1967, año en que la editorial Jorge Álvarez publicó Crónicas de Norteamérica en la célebre colección Crónicas dirigida por Julia Constenla desde 1965. Las doce crónicas seleccionadas incluían autores muy transitados por los lectores locales, como Faulkner, Hemingway o Capote, y otros nunca antes traducidos, como el escritor negro contemporáneo James Baldwin. La contemporaneidad se anunciaba desde el diseño de tapa, a cargo Roberto Alvarado, integrante del departamento de fotografía del Di Tella: la imagen de Tío Sam blandiendo una pequeña 
flor blanca traduce en clave pacifista el gesto imperioso con que Uncle Sam interpelaba, en la "versión original" de la imagen, a los jóvenes estadounidenses: «I Want You for the U.S. Army». Las Crónicas de Norteamérica venían así a establecer un diálogo vigoroso con el presente literario de los Estados Unidos. Pero el criterio de selección de textos e imágenes no sólo arraigaba fuertemente en el presente, sino en un presente estadounidense considerado de rebeldía, compromiso y fuerte crítica social, de ahí la alusión directa al pacifismo y la referencia a las luchas por los derechos civiles de los negros explícitamente cifrada en la elección de Baldwin, un año antes del asesinato de Luther King.

Anotado por Ricardo Piglia y traducido por Aída Aisension, Pirí Lugones, Pedro Sandoval, Jesús Pacheco, Juan Godo Costa, Ernesto Corbalán, Nicolás Suescún y J. Ruiz, el volumen contó con un explicativo prólogo de Alberto Ciria:

Parcial selección de un vasto universo literario (recorrido por) una línea profunda, una verdadera constante [...]: rebeldía, inconformismo, espíritu de crítica social en su caso pero desde adentro de la propia sociedad criticada. [...] Parece obvio que la gran mayoría de los escritores norteamericanos se han convertido en testigos y en críticos de su tiempo, en una sociedad que ha hecho del dissent -el disenso o la disensión con las políticas o medidas oficiales- uno de sus valores espirituales [...]. Los correlatos entre realidad y literatura podrían multiplicarse, pero aquí no se trata de justificar una selección sino de explicarla. La constante de la rebeldía, del inconformismo, del espíritu de crítica social, trasciende de las narraciones elegidas. La variedad y el tono de las mismas habla por sí solo, no ya únicamente de una literatura, sino de un país.

Al seleccionar aquello que revela la crítica social «desde adentro», el disenso que anida en el corazón de los USA, los editores promueven una lectura identificatoria en el disenso. Se trata, pues, de una selección en que la exploración de los vínculos entre realidad y literatura toma de entrada partido por la visión del «enemigo interno» del coloso imperial. Esta estrategia editorial será reforzada por las estrategias de traducción desplegadas por algunos de sus traductores, tal como veremos a continuación.

\section{Estrategias de traducción: «aclimatar rabiosamente»}

En «Traductores en el Siglo», Patricia Willson advierte un nuevo fenómeno traductor vinculado con la importación del llamado «policial negro» o novela negra en la década del setenta:

El uso de un fraseo antes impensado para una traducción: el que emplea Ricardo Piglia en su versión de «Los asesinos», relato de Ernest Hemingway cuyo original en inglés data de la primera posguerra: «Tenés que ir más al cine. Las películas son algo bárbaro para un piola como vos», le dice un personaje a otro en la traducción de Piglia. Este fraseo no es errático sino constante; obedece, pues, a una decisión consciente del traductor. Piglia aclimata rabiosamente: quiere que ese texto de Hemingway sea referente para la lectura de sus propias ficciones. Pero además, el efecto de anexión que genera el voseo y las elecciones léxicas rioplatenses es una forma de situarse frente a lo foráneo. ${ }^{27}$

El giro identificado por Willson en el policial negro norteamericano se proyectó desde la década del sesenta hacia la del setenta. Y 1969 puede considerarse el año de ese pasaje. 


\section{De Jorge Álvarez a Tiempo Contemporáneo (pasando por Ricardo Piglia)}

En agosto de 1969 la revista Los Libros anunciaba, en su sección «Informaciones», la publicación de dos colecciones en que «la atención mayor [estaría] puesta en las traducciones»: Clásicos de Nuestro Tiempo de la Editorial Jorge Álvarez y la Serie Negra de Tiempo Contemporáneo. Pese a los anuncios y a la promesa de contemporaneidad que parece marcarlas, estas colecciones no serían coetáneas sino sucesivas. De los Clásicos de Nuestro Tiempo sólo llegaría a editarse una traducción: Memorias del Subsuelo de Dostoievski en versión indirecta de Floreal Mazía. El cierre inesperado de Jorge Álvarez pondría fin, como ya he señalado, a este y a otros proyectos de traducción en curso.

Entre la interrupción de Jorge Álvarez y el inicio de la Serie Negra de Tiempo Contemporáneo se establece una línea de continuidad en lo referente a las prácticas traductoras. Esta hipótesis, que se corrobora en los textos, aparece implícitamente formulada en el modo en que las traducciones de ambas editoriales se confunden en la memoria de una figura clave de la época, Tomás Eloy Martínez:

[El] jefe de redacción de la revista [Primera Plana] entre 1962 y 1969, considera que

JA tenía una propuesta novedosa para el mercado argentino, ya que no sólo publicaba libros inusuales como La Traición de Rita Hayworth de Manuel Puig o Nanina de Germán García, sino que traducía policiales norteamericanos trasladando el slang americano al argot porteño, algo absolutamente infrecuente para las editoriales argentinas, que generalmente traducían en un español neutro. ${ }^{28}$

Si repasamos el catálogo de la Editorial Jorge Álvarez no hallaremos, por cierto, «policiales norteamericanos». Estos fueron más bien especialidad de la Serie Negra de Tiempo Contemporáneo, iniciada en 1969 bajo la dirección de Piglia. Sin embargo, Martínez no se equivoca: condensa en un mismo recuerdo dos eventos similares. El lapsus del editor de Primera Plana parece refrendar la hipótesis de una continuidad de las prácticas aclimatadoras desde los sesenta hacia los setenta.

Activa entre 1963 y 1969, la editorial Jorge Álvarez constituyó un vector de difusión de la literatura argentina y un agente modernizador del campo editorial. Pero la publicación de autores argentinos y de narrativa latinoamericana convivió con un criterio de selección ecléctico plasmado en la diversidad de materias y géneros cubiertos por su catálogo. Prácticamente todos los tópicos que interpelaban a los jóvenes intelectuales de izquierda en la década del sesenta están representados en su fondo. El haber sido puntal de boom del libro argentino no le impidió ser una editorial, como tantas en este período, eminentemente traductora: de la veintena de colecciones que constituyen su catálogo más de la mitad está total o parcialmente integrada por traducciones hechas por una cuarentena de traductores identificados y otras tantas decenas de traductores anónimos. La omnipresencia de la traducción en el catálogo de Jorge Álvarez apuntala nuestra hipótesis inicial del vínculo estrecho entre literatura extranjera y literatura nacional en el período del «boom del libro argentino». Sin embargo, en el caso de Jorge Álvarez hay dos elementos que refuerzan la conjetura: el primero es el efecto de fusión de las tradiciones nacionales y regionales generado por los libros misceláneos articulados en torno a un tema, novedosa modalidad promovida por este editor. En efecto, las Crónicas combinaban textos de Cortázar, Walsh o Piglia con relatos de Hemingway, Capote o Bierce. Esta práctica se extendió significativamente a otras colecciones: en 1966 Álvarez lanzó la colección Narradores Americanos, cuyo criterio de selección parece fundarse en una 
concepción "panamericanista» de la literatura, conforme a la cual convivieron en un mismo catálogo obras de Bierce, Capote, Carpentier, Viñas, Piglia, Walsh, Traba, entre otros narradores del norte, centro y sur «americano». El segundo elemento que refuerza la hipótesis apuntada es la variedad de lengua utilizada en ciertas traducciones, en particular aquellas hechas por Susana «Pirí» Lugones.

Para retomar el caso de Crónicas de Norteamérica, propongo analizar brevemente la traducción del texto de James Baldwin, «Esta mañana, esta tarde, tan pronto», que firma Pirí Lugones. Se trata del relato de un retorno: un músico negro, refugiado en París, regresa a los Estados Unidos tras casi diez años de distancia. En París ha triunfado como músico y como actor. Tuvo un hijo mestizo, Paul, con una mujer nórdica, Harriet. La lengua materna de Paul es el francés. El diálogo familiar está salpicado de expresiones en francés y de comentarios metalingüísticos. Así traduce Pirí Lugones la escena matinal con que se abre el relato, el día previo al temido retorno a los Estados Unidos:

- Dios mío, tu padre está chiflado esta mañana ¿no? [...] Es porque teme que sus canciones no gusten en Nueva York. Tu padre es un artiste, mon chou y les artistes son gente misteriosa. Millones de personas lo están esperando en Nueva York, le ruegan que vaya, y le darán un montón de dinero. Decile que está equivocado.

- Por supuesto estás equivocado, sos tonto [dice Paul].

- Les vas a poner la tapa en Nueva York, ya verás.

- Mais bien sûr -contestó Paul dubitativamente. No sabe muy bien qué es eso de poner la tapa.

- Ponerles la tapa -dice Harriet- significa avoir un succès fou. Pero pronto entenderás todas las expresiones norteamericanas.

Este diálogo bilingüe, que parece extraído de una novela argentina del exilio avant la lettre , revela que Lugones adopta un término medio entre la aclimatación absoluta y la exotización a ultranza: solo «traduce» la variedad de inglés afroamericano de Baldwin al rioplatense. El recurso al voseo pronominal y verbal, a expresiones rioplatenses como «poner la tapa», y la traducción de la toponimia, son claras estrategias aclimatadoras, sostenidas a lo largo de su traducción. El respeto de la onomástica y de los giros en francés mantiene, en cambio, la multiplicidad lingüística necesaria para recrear el clima de doble desarraigo familiar, de doble no pertenencia propia de este relato del exilio.

La Serie Negra de Tiempo Contemporáneo tomó el relevo de las estrategias editoriales orientadas a la selección de autores norteamericanos ${ }^{29}$ y de las estrategias de traducción que recurren a una variedad de lengua anclada en lo local, como señala Willson. En 1969 Tiempo Contemporáneo lanza la colección con un primer número misceláneo: Cuentos policiales de la serie negra. Integran el volumen ocho relatos con traducciones rioplatenses de Fredric Brown, James M. Cain, Raymond Chandler, Peter Cheyney, Erle Stanley Gardner, Dashiell Hammett, Ross MacDonald -los relatos de Hammett, Chandler y Gardner fueron traducidos por Floreal Mazía; el resto por Ricardo Ocampo, seudónimo de Ricardo Piglia; la traducción del prólogo es de Irene Cusien-, anotados y prologado por Emilio Renzi, seudónimo de Ricardo Piglia, quien dirige la colección. En el prólogo, RenziPiglia retoma indirectamente la línea propuesta por Ciria al sostener que la novela negra es literatura social de notable calidad cuyo origen debe pensarse, no en el policial de enigma, sino en el interior de cierta tradición propia de la literatura norteamericana, que hunde sus raíces en la narrativa norteamericana crítica y halla dos precedentes ineludibles en Santuario de Faulkner y «Los asesinos» de Hemingway, cuya traducción precisamente citaba Willson. 
Así pues, los agentes involucrados, el criterio de selección, el contenido de los paratextos, todo parece indicar una continuidad con la estrategias editoriales y de traducción plasmados en Crónicas de Norteamérica. No todas pero muchas de las traducciones de la Serie Negra de Piglia recurrirán a una variedad local para decir lo foráneo. Rodolfo Walsh y Floreal Mazía en particular optarán por esta estrategia aclimatadora, con los mismos rasgos mixtos detectados en las traducciones de Pirí Lugones: el voseo convive con el respeto de la onomástica y toponimia foránea. En rigor, estas traducciones no borran la extranjeridad, sino que vierten el inglés "americano» a una variedad «americana» del castellano, conforme a la lógica inclusiva que rige la selección de autores en las Crónicas y en la colección Clásicos Americanos de Jorge Álvarez.

Por cierto, en la Serie Negra no solo se tradujo del inglés americano. La gran novedad fue la inclusión de dos novelas del ex mafioso corso-suizo José Giovanni. En 1969, después de los Cuentos policiales de la serie negra, se publicó A todo Riesgo de Giovanni en traducción de Florial Mazía. A todo Riesgo pone en escena la huída de dos mafiosos, Raymond Naldi y Abel Davos, desde Italia hacia Francia. En la traducción la toponimia italiana y francesa convive con el más rabioso voseo. Mazía mantiene la estrategia mixta. Sin embargo, entre carreras motorizadas y persecuciones de a pie, imprevistamente aparece una figura que introduce en el relato el filón de una historia ajena, es decir, propia: «La moto lo sacudía como un caballo salvaje sacude el diestro cuerpo de un gaucho».

No sabemos si el gaucho figura en el «texto original» de Giovanni. Es improbable y quizá no importe. Cuando menos no parecía importar en 1969, cuando Gelman podía jugar a ser Sidney West, o su traductor, y ese juego de versiones considerarse una de las mejores obras nacionales del año, como pensaba Martínez, y valorarse por su capacidad para «denunciar la propiedad privada de la escritura» y de la literatura toda, como creía Sasturain, parafraseando a Borges.

\section{«Mirarnos en Gombrowicz»: más allá de 1969, el exilio}

Suele decirse que la literatura argentina es consustancial a la experiencia del exilio. Lo mismo podría afirmarse de la traducción, tarea mil veces asumida por desterrados a lo largo y a lo ancho de la geografía de tantas diásporas. De hecho, existe en nuestra historia cultural un mito fundado en una escena de traducción que involucra a un exiliado, polaco, y a un grupo de amigos que reunió un dinero para que el exiliado pudiera subsistir un tiempo traduciendo, con asistencia baqueana, del polaco al castellano, su propia obra. Dura labor que el exiliado comenzó «sin entusiasmo, solamente para sobrevivir durante los meses próximos; [sus] ayudantes americanos también lo encaraban con resignación, como un favor que había que hacer a una víctima de la guerra» ${ }^{30}$. Ese exiliado, Witold Gombrowicz, murió en París el 24 de julio de 1969. En agosto de 1969, la revista Los Libros fue escenario de la elaboración del mito: en la sección «Presencias» Germán García escribe una despedida en la que evoca la traducción colectiva o autotraducción asistida de Ferdydurke. Muerto Gombrowicz, la escena pasaba de la historia al mito: «En 1947 Editorial Argos publicó la primera edición castellana y a Gombrowicz le gusta poner el nombre de sus 21 traductores del polaco» ${ }^{31}$.

Hecho de exilios y traducciones, el mito nacido en 1969 también fue signo de lo que vendría después de 1969. El proceso de radicalización ideológica, violencia política y represión del aparato estatal y paraestatal, que precedió al golpe de 1976, cortaría el desarrollo y la modernización editorial gestados en el clima de ebullición cultural y 
política que dominó la década del sesenta y primeros setenta. A partir de la segunda mitad de los setenta, y aun antes, muchos de los escritores, traductores y editores mencionados en estas páginas saldrían al exilio. En días de apuro, cuando aun no había trabajo firme ni contactos suficientes, no pocos se convirtieron en los Gombrowicz de algún editor solidario o compatriota bien colocado ${ }^{32}$. En ese trance del exilio quizá alguno de ellos haya recordado la profética frase con que Germán García cerraba en 1969 su despedida: «Ahora nos toca a nosotros mirarnos en Gombrowicz ».

\section{NOTAS}

1. Amelia Aguado, «La consolidación del mercado interno», José Luis de Diego (comp.), Editores y políticas editoriales en Argentina 1880-2000, Buenos Aires: FCE, 2007, p.130.

2. Eduardo Anguita y Martín Caparrós, La Voluntad. Una historia de la militancia revolucionaria en la Argentina. Tomo I: 1966-1969, Buenos Aires: Booket, 2006, p. 477.

3. Juan Sasturain, «Juan Gelman: el peligroso oficio del poeta», Los Libros, n 9, Buenos Aires, julio de 1970, p. 8.

4. Alberto Julián Pérez, «Gelman y la poesía norteamericana: Los poemas de Sidney West», Actas del VII Congreso Internacional Orbis Tertius de Teoría y Crítica Literaria. La Plata: UNLP, 2009.

5. Tal como sostiene Gustavo Sorá: «Aun cuando esta fuerza de alteridad pasa a ser negada en favor de una legitimación de los logros colectivos en la clave de la 'autodeterminación', la misma es una constante estructural». En Traducir el Brasil. Una antropología de la circulación internacional de las ideas, Buenos Aires: Libros del Zorzal, 2003, p. 33.

6. Mirta Lobato y Juan Suriano, Atlas Histórico de la Nueva Historia Argentina, Buenos Aires: Sudamericana, 2000, p. 454.

7. En mayo de 1969 se prohíbe la exhibición de Teorema de Pasolini. En julio, el juez Edmundo Sammartino condena a un año de prisión en suspenso al escritor Germán García y a Juan José Lecuona, gerente de Jorge Álvarez, por la publicación de Nanina; en agosto le secuestran sesenta ejemplares de obras afectadas por la ley de represión del comunismo. Librerías y editoriales como Tres Américas y Paidós también son objeto de procedimientos policiales. En septiembre, personal de coordinación federal secuestra la edición completa de la publicación periódica Siglomundo, del Centro Editor de América Latina. Véase Andrés Avellaneda, Censura, autoritarismo y cultura: Argentina 1960-1983, Buenos Aires: CEAL, 1986, pp.102-103.

8. Mariano Mestman, «Postales del cine militante en el mundo», Kilómetro 111, Buenos Aires, 2001, p.13.

9. Louis Marcorelles, «La hora de los hornos: la prueba del directo», El lagrimal trifurca, ํㅜ 5, Rosario, junio-septiembre de 1969, p 55. Sin mención del traductor.

10. Oscar Terán, Historia de las ideas en la Argentina, Buenos Aires: Siglo XXI, 2008, pp.284-287.

11. Horacio Tarcus, «El Mayo Argentino», OSAL, año IX, no 24, octubre de 2008, p.171.

12. Álvarez recuerda que le «había agarrado el ataque por las revistas» y había intentado convencer a Sartre de traducir Temps Modernes. En Memorias, Buenos Aires: Libros del Zorzal, 2013, p. 45. 
13. Del francés se tradujeron obras de Alphonse Allais, René Barjavel, Léon Bloy, Petrus Borel, Balzac, Julio Verne en traducción de Raúl Gustavo Aguirre, Peyrefitte, Boris Vian, Paul Nizan y Yourcenar, en traducción de Hernán Cueva. Y en el rubro de la crítica: El espacio literario de Maurice Blanchot, Cuatro narradores franceses de hoy de Claude Simon, Tres clásicos de la novela francesa: Stendhal, Balzac, Flaubert de Hugo Friedrich, la compilación crítica titulada Proust, fue traducida por Patricio Canto; y Sartre por Sartre compilado por Juan José Sebreli.

14. La importación de literatura en lengua alemana privilegió a Kafka y Brecht, Goethe, Durenmatt, Hesse y el ensayo autobiográfico de Nietzsche Mi Hermana y yo. Las críticas en revistas -como la reseña colectiva de Jorge Lafforgue en $n^{\circ} 2$ de Los Libros- y la publicación de teoría y crítica especializada interactuó con la importación literaria: Lukacs y Adorno sobre el realismo; Descripción de una forma: Kafka de Martin Walser y Kafka de Marthe Robert, Lukacs Brecht y la situación actual del realismo socialista de Francisco Posada.

15. Cronistas, guionistas y novelistas: Pietro Aretino, Alberto Bevilacqua, Casanova, Pavese, María Ragazzi, entre otros.

16. Traducciones de Dostovieski, Tosltoi, Gogol, Gorki, Solyenitzin, en versiones indirectas o reediciones españolas, como las de Rafael Cansinos Assens editadas por el CEAL.

17. La Pleyade editó El Buen Soldado Shveik de Aroslav Hašek, traducido de la versión francesa por Estela Canto.

18. Del chino Yuan-chün la Breve historia de la literatura clásica china, por Juárez Editor; Cuentos chinos con fantasmas. Dinastías Tang a Tsing, en versión indirecta de Bernardo Kordon. Del Japonés Tres maestros del haiku: Basho, Buson, Issa con introducción, traducción y notas de Osvaldo Svanascini, editado en 1966 por el Instituto Argentino-Japonés de Cultura y reeditado por Clany y Cia. en 1969. En cuanto a la poesía vietnamita, David Fernández traduce del italiano, para $E l$ Lagrimal Trifurca, cuatro poemas anónimos y uno de Nguyen Thiem, precedidos de una nota: «los siguientes son poemas escritos por guerrilleros vietnamitas muertos en batalla. Fueron recuperados con sus cadáveres en los campos y fechas indicados». En 1969 estaban en preparación las compilaciones Los poetas de la dinastía Tang y Antología de la literatura japonesa, todas ellas indirectas, excepto la de Rashomon y otros cuentos de Akutagawa, realizada por el traductor y artista plástico argentino-japonés Kasuya Sakai. En 1970 el CEAL introduciría en el mercado lector literaturas escasamente traducidas: china, japonesa, india, hebrea, árabe.

19. Emecé editó a Nicholas Blake, Chase y Ross MacDonald. Pero el acontecimiento de 1969 fueron los primeros dos números de la Serie Negra de Tiempo Contemporáneo, dirigida por Piglia y traducida por Walsh, Mazía, Estela Canto, Juana Bignozzi, entre otros.

20. Si bien la ciencia ficción en la Argentina es sinónimo de Minotauro, en 1969 Ciencia ficción: Realidad y psicoanálisis de Eduardo Goligorsky y Mary Langer salió en Paidós, aunque reseñado por el mismísimo Paco Porrúa en Los Libros. Carlos Pérez editó una introducción de Jean Charles Pichon titulada Ciencia ficción: de Verne a Bradbury.

21. De 1969 es la compilación de Rodolfo Alonso Editor titulada Vampiros y otros monstruos, que incluye la novela inconclusa de Byron, Frankestein de Mary Shelley, Vathek de William Beckford y un relato de Polidori, todos ellos con prólogo y traducción del profesor y traductor Enrique Luis Revol. La ilustración de tapa es del artista plástico argentino Sergio Camporeale. Por lo demás, Brújula publicó el Frankestein de Mary Shelley en traducción de Aníbal Leal y dibujo de portada de Hermenegildo Sabat.

22. Isabella Cosse, Pareja, sexualidad y familia en los años sesenta, Buenos Aires: Siglo XXI, 2010.

23. Rodolfo Alonso Editor publica Cartas, en traducción de Amanda Forns; Los crímenes del amor, La Marquesa de Gange, en traducción de Raúl Gustavo Aguirre; Editores Dos publica El conde de Oxtiern y la editorial Brújula Cuentos, historietas y fábulas; Quintaria Los crímenes del amor, Escritos políticos y Eugenia de Franval; la editorial rosarina Aries Carta a un ciudadano de París, con prólogo de Nicolás Rosa "Sade o el texto falso". Traducciones literarias 
apuntaladas mediante la importación de textos críticos locales y extranjeros sobre Sade: la traducción del número especial de Tel Quel titulado El pensamiento de Sade con textos de Klossowski, Barthes, Sollers y otros publicada por Paidós; Sacher Masoch \& Sade de Gilles Deleuze por la Editorial Universitaria de Córdoba, y otros.

24. Daniel Divinsky, «Breve historia de Ediciones de La Flor: Editar en la Argentina ¿un oficio insalubre?», Buenos Aires: La Biblioteca, no 4-5, verano 2006, p. 431.

25. Maite Alvarado y Renata Rocco-Cuzzi, «Primera Plana el nuevo discurso periodístico de la década del 60», Buenos Aires: Punto de Vista, n²2, diciembre de 1984, p. 28.

26. Miguel Grinberg, «El sabor de la eternidad», Suplemento Radar, Página/12, 21/05/2006.

27. Patricia Willson, «Traductores en el Siglo», Buenos Aires: Punto de Vista, $\mathrm{n}^{\circ}$ 89, marzo-abril de 2007, p. 24.

28. Ana Mosqueda, «La editorial Jorge Álvarez, cenáculo de los sesenta», La Biblioteca, nº 4-5, Buenos Aires, 2006, p. 486. Sobre la trayectoria de Tiempo Contemporáneo, véase: Emiliano Álvarez, «Una editorial de la Nueva Izquierda. Tiempo Contemporáneo», Políticas de la memoria, $\mathrm{n}^{\circ}$ 13, verano 2012/2013, pp. 143-155.

29. Esta colección lleva doblemente la marca de lo «importado», pues su nombre calca el de una célebre colección francesa contemporánea: la Serie Noire creada en 1945 por Gallimard y dirigida por Georges Duhamel, traductor de Steinbeck y Hemingway.

30. Gombrowicz citado en Rafael Cippolini, «Ferdydurke forrado de niño. Biografía de una versión», Otra Parte, ㄲo 4, Buenos Aires, primavera-verano de 2004.

31. Germán García, «Leer a Gombrowicz», Los Libros, nº 2, Buenos Aires, agosto de 1969, p.12.

32. Falcón Alejandrina, «Exiliados argentinos en la industria editorial española: representaciones, focos laborales y redes de solidaridad (1974-1983)», Revista Eletrônica da Associação Nacional de Pesquisadores e Professores de História das Américas, $\mathrm{n}^{\circ}$ 19, juliodiciembre de 2015. En línea: http://revistas.fflch.usp.br/anphlac/issue/view/188. Consulta: 01/06/2016.

\section{RESÚMENES}

El propósito general de este trabajo es explorar el lugar de la traducción a finales del llamado «boom editorial de la literatura nacional» centrándonos en el año 1969. Para la construcción del objeto se han articulado tres perspectivas: las representaciones colectivas del traductor y la traducción, la traductografía y los criterios de selección y, por último, las estrategias traductoras más representativas del período.

The general purpose of this work is to explore the place of translation at the end of what has been called the 'publishing boom of national literature', with a focus on the year 1969. In constructing the object, three perspectives have been articulated: collective representations of the translator/translation; translatography and selection criteria; and translation strategies that most notably represent the period.

L'objectif général de cet article est d'explorer le rôle de la traduction dans la culture argentine en 1969. Dans ce but, ce travail analyse successivement les représentations collectives du traducteur, la traductographie, les critères de sélection et les stratégies de traduction. 
ÍNDICE

Mots-clés: histoire de la traduction, études sur l'édition, littérature argentine, XXe siècle.

Palabras claves: historia de la traducción, estudios de edición, literatura argentina, Siglo XX.

Keywords: history of translation, publishing studies, Argentinean literature, twentieth century.

\section{AUTOR}

\section{ALEJANDRINA FALCÓN}

UBA/ IESLV

Universidad de Buenos Aires. Consejo Nacional de Investigaciones Científicas y Técnicas. Instituto de Historia Argentina y Americana «Dr. Emilio Ravignani», Facultad de Filosofía y Letras, Proyecto Ubacyt «Cercanías: literatura argentina y publicaciones periódicas», Buenos Aires, Argentina / Instituto de Enseñanza Superior en Lenguas Vivas «Juan Ramón Fernández», Buenos Aires, Argentina.

alejafal@gmail.com 